\title{
Electrochemical Cell Loss Minimization in Modular Multilevel Converters Based on Half-Bridge Modules
}

\author{
Gianluca Brando ${ }^{1, *}$, Efstratios Chatzinikolaou ${ }^{2}$, Dan Rogers ${ }^{2}$ and Ivan Spina ${ }^{1}[$ \\ 1 Department of Electrical Engineering and Information Technology, University of Naples Federico II, \\ 80125 Naples, Italy; ivan.spina@unina.it \\ 2 Energy and Power Group, Department of Engineering Science, University of Oxford, Oxford OX1 3PA, UK; \\ stratos_hatz@hotmail.com (E.C.); dan.rogers@eng.ox.ac.uk (D.R.) \\ * Correspondence: gianluca.brando@unina.it; Tel.: +39-0817683233
}

Citation: Brando, G.; Chatzinikolaou,

E.; Rogers, D.; Spina, I.

Electrochemical Cell Loss

Minimization in Modular Multilevel

Converters Based on Half-Bridge

Modules. Energies 2021, 14, 1359.

https://doi.org/10.3390/en14051359

Academic Editor: Jinliang Yuan

Received: 21 January 2021

Accepted: 24 February 2021

Published: 2 March 2021

Publisher's Note: MDPI stays neutral with regard to jurisdictional claims in published maps and institutional affiliations.

Copyright: (c) 2021 by the authors. Licensee MDPI, Basel, Switzerland. This article is an open access article distributed under the terms and conditions of the Creative Commons Attribution (CC BY) license (https:// creativecommons.org/licenses/by/ $4.0 /)$.

\begin{abstract}
In the developing context of distributed generation and flexible smart grids, in order to realize electrochemical storage systems, Modular Multilevel Converters (MMCs) represent an interesting alternative to the more traditional Voltage Source Inverters (VSIs). This paper presents a novel analytical investigation of electrochemical cell power losses in MMCs and their dependence on the injected common mode voltage. Steady-state cell losses are calculated under Nearest Level Control (NLC) modulation for MMCs equipped with a large number of half-bridge modules, each directly connected to an elementary electrochemical cell. The total cell losses of both a Single Star MMC (SS-MMC) and a Double Star MMC (DS MMC) are derived and compared to the loss of a VSI working under the same conditions. An optimum common mode voltage injection law is developed, leading to the minimum cell losses possible. In the worst case, it achieves a $17.5 \%$ reduction in cell losses compared to conventional injection laws. The analysis is experimentally validated using a laboratory prototype set-up based on a two-arm SS-MMC with 12 modules per arm. The experimental results are within $2.5 \%$ of the analytical models for all cases considered.
\end{abstract}

Keywords: lithium batteries; los minimization; Modular Multilevel Converters; optimization methods

\section{Introduction}

The rapid advances in energy storage technologies that have occurred in recent years, together with the urgent issue of environmental pollution, have driven innovative power electronic solutions that, apart from the main function of power conversion, provide additional functionality, such as minimizing system energy losses while assuring the maximum lifetime of the storage devices.

One set of promising converter topologies are based on the series connection of single half-bridge or full-bridge modules [1], each interfaced with a storage device, such as electrochemical cells or super-capacitors. The connection between the power module and the storage device can be either direct or occur via an additional DC/DC converter [2]. The series connection of a fixed number of modules represents an arm [3] of the converter. Based on the number of arms and their relative configuration, different versions of the Modular Multilevel Converter (MMC) can be realized [4,5].

The star connection of $\mathrm{n}$ arms can be adopted in order to realize the simplest $\mathrm{n}$ phase AC output converter [6], i.e., Single Star MMC (SS-MMC). On the other hand, a Double Star (DS) connection of $2 \mathrm{n}$ arms leads to the DS-MMC [7], where each pair of arms of the same phase are interfaced by two buffer inductances, providing both an $\mathrm{n}$ phase AC output and a DC interface. Both architectures have been widely proposed in several contexts, including traction applications [8-12] and transformerless grid connected storage systems [13-16].

The inherent modularity of MMCs helps minimize the system maintenance costs and generates fault tolerance features $[14,17,18]$. In the case of failure, the failed module can be bypassed without interrupting the operation of the system. The improved system reliability 
allows scaling to high voltages by connecting a very high number of modules in series. Therefore, a direct (transformerless) connection to high-voltage grids is feasible [13] by means of switches characterized by relatively low-voltage ratings, leading to a significant cost reduction and competitive total system efficiency [15]. A large number of modules also results in smaller rates-of-change of voltage (since the output voltage of each module is only a small percentage of the peak output voltage), strongly reducing Electro-Magnetic Interference (EMI)-related issues.

In the context of electrochemical storage devices [19], in order to safeguard the cells and guarantee the highest number of charge/discharge cycles, it is necessary to keep all of the cells balanced in terms of their State of Charge (SoC). While traditional converters are normally equipped with an additional Battery Management System [20], MMC solutions inherently provide this balancing functionality at the module level $[12,16,21,22]$.

As an additional advantage, these modular converter designs lead to a significant reduction of the converter switching losses, especially when a large number of modules (and subsequently, voltage levels) are available [11]. In these cases, high switching frequency Pulse Width Modulation (PWM) schemes can be replaced by Nearest Level Control (NLC) modulation [23]. NLC generates a nearly-sinusoidal AC output by combining the DC voltages of the converter modules while driving the devices with a switching frequency equal to the fundamental, thus producing negligible switching losses. However, since at least one device per module is always in the current path, for large-scale systems, this approach could result in a substantial increase of conduction losses. For this reason, the careful selection of low-voltage Metal Oxide Semiconductor Field Effect Transistors (MOSFETs) optimized for low on-state resistance is necessary.

In most studies to-date where efficiency is considered, MMC solutions are compared with conventional Voltage Source Inverters (VSIs), but only power electronic losses are taken into account, whereas losses occurring in electrochemical cells are ignored [11]. This approach can be misleading; indeed, according to [15], MMC cell losses can form a significant fraction of overall system losses and will disproportionally affect MMC-type designs because the cells are operated under a low-frequency pulsed current (as opposed to a constant DC current in a VSI). On the other hand, this suggests a considerable margin for improvement, since the potential reduction of the MMC cell losses would have a great impact on the total system efficiency.

These considerations underline the need for a more detailed study where the possibility to influence the MMC cell power losses should be investigated. In fact, although many authors recognize the common mode reference [5] as a degree of freedom for the MMCs, no analysis of its effect on the cell power losses has been conducted.

In the context of MMCs comprising a large number of half-bridge modules, each including an elementary electrochemical cell and driven by NLC modulation, this paper presents a novel analytical investigation where the calculation of the cell losses is generalized for any common mode voltage value, so that the dependence of the cell losses from the common mode component is analyzed. Moreover, an optimum common mode voltage injection law is developed, assuring the minimization of cell power losses.

The proposed optimum strategy is compared with traditional approaches, showing a significant decrease in the cell losses: Considering that MMC cell losses can be a considerable fraction of total system losses, their minimization can significantly improve the system efficiency and reduce detrimental cell heating.

The total cell losses of an SS-MMC and DS-MMC are derived in all of the considered cases and compared with the loss associated with an equivalent VSI solution. Finally, all of the mathematical derivations are validated by means of an experimental set-up (see Figure 1) based on a two-arm SS-MMC with 12 modules per arm, each containing an elementary lithium ion cell. The results exhibit good agreement with the analytic model and demonstrate the effectiveness of the proposed strategy. 

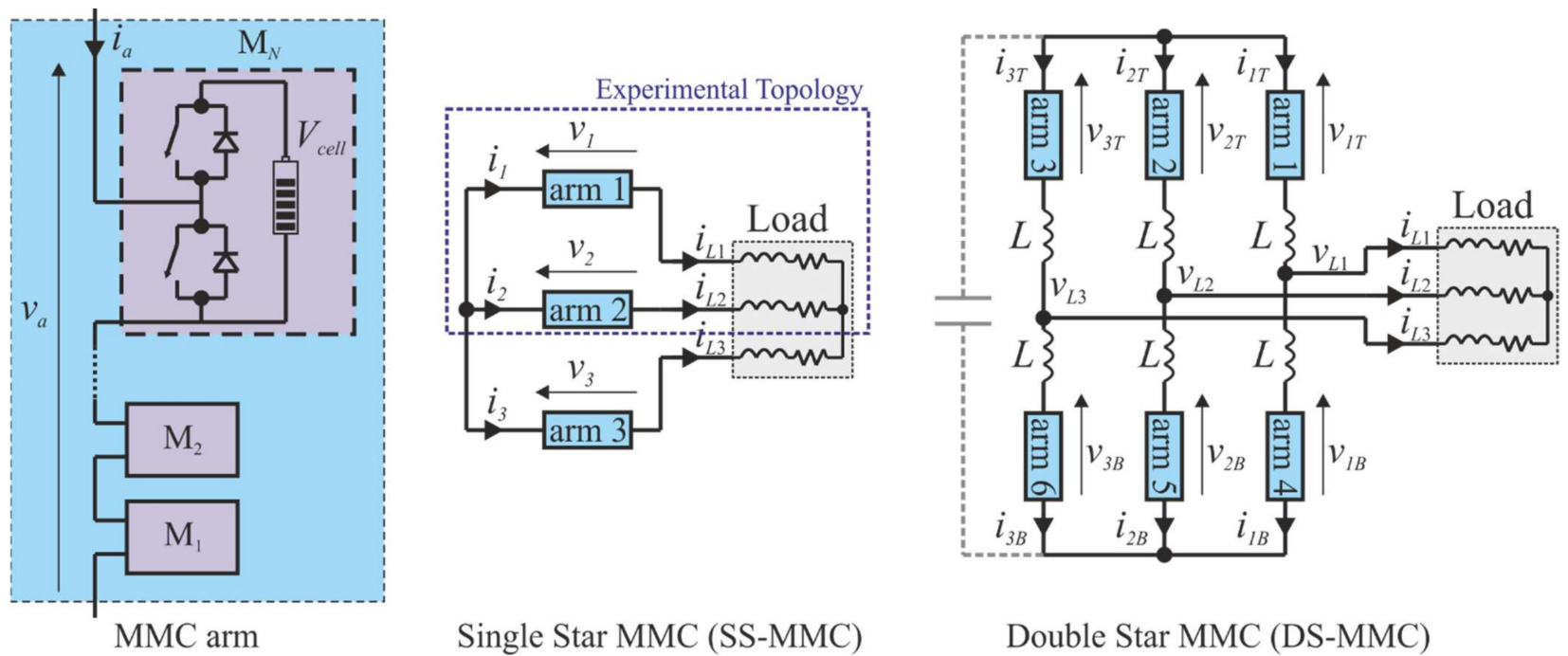

Single Star MMC (SS-MMC)

Double Star MMC (DS-MMC)

Figure 1. Modular Multilevel Converters (MMCs).

\section{Description of the System}

Figure 1 shows a single generic converter arm, composed of $N$ half-bridge modules; $v_{a}$ and $i_{a}$ represent the total arm voltage and the arm current, respectively. Each module is driven by an electrochemical cell at the voltage $V_{\text {cell }}$, which is the average cell voltage. The SS-MMC and DS-MMC feed symmetrical three-phase loads. Given the possibility of the DS-MMC exchanging power through a DC interface, an optional capacitor (gray dashed line) has also been added. The experimental topology is outlined.

When a module is activated, the corresponding upper switching device is turned $\mathrm{ON}$ and its output voltage equals $V_{\text {cell }}$, while the arm current $i_{a}$ flows in the cell. When a module is de-activated, its output voltage is zero and no current flows in the cell, i.e., the cell is bypassed.

When NLC modulation is implemented, the total number of active modules required to synthesize the instantaneous arm reference voltage $v_{a}^{*}$ is given by

$$
N_{\text {on }}=\operatorname{round}\left(v_{a}^{*} / V_{\text {cell }}\right) \text {. }
$$

In this case, State of Charge (SoC) balancing between the cells can be achieved by choosing which cells contribute to the output arm voltage $v_{a}$ based on their SoC, i.e., when the system is charging, the $N_{\text {on }}$ cells with the lowest $\mathrm{SoC}$ will be activated, whereas during discharge, the $N_{\text {on }}$ cells with the highest $\mathrm{SoC}$ will be placed in the current path.

A second balancing action should be implemented in order to equalize the mean SoCs between the arms through the injection of a proper circulating current value. Since the circulating current is normally a small percentage of the nominal current and is only present during cell balancing [11], its contribution to the losses is not significant and will be neglected in the present discussion.

SS-MMC

With reference to an SS-MMC, denoting the three arm reference voltages as $v_{1}^{*}, v_{2}^{*}, v_{3}^{*}$, it is possible to define the following common mode component:

$$
v_{0}^{*}=\left(v_{1}^{*}+v_{2}^{*}+v_{3}^{*}\right) / 3
$$

Based on Equation (2), the reference voltages can be written as

$$
\left\{\begin{array}{l}
v_{1}^{*}=v_{1, d}^{*}+v_{0}^{*} \\
v_{2}^{*}=v_{2, d}^{*}+v_{0}^{*}, \\
v_{3}^{*}=v_{3, d}^{*}+v_{0}^{*}
\end{array},\right.
$$


where $v_{k, d}^{*}$ (with $k=1,2,3$ ) is, by definition, the differential component of $v_{k}^{*}$. Since the load currents are not affected by $v_{0}^{*}$, it represents an effective degree of freedom in the arm modulation.

As $0 \leq v_{k}^{*} \leq N V_{\text {cell }}(k=1,2,3)$, the quantity $v_{0}^{*}$ must fulfill the following constrains:

$$
\left\{\begin{array}{l}
v_{0}^{*} \geq-\min \left(v_{1, d}^{*}, v_{2, d}^{*}, v_{3, d}^{*}\right)=v_{0, \min }^{*} \\
v_{0}^{*} \leq N V_{\text {cell }}-\max \left(v_{1, d}^{*}, v_{2, d}^{*}, v_{3, d}^{*}\right)=v_{0, \max }^{*}
\end{array} .\right.
$$

The common mode voltage can be decomposed into its DC and AC components:

$$
v_{0}^{*}=v_{0, D C}^{*}+v_{0, A C}^{*}
$$

In a normal steady-state condition, the differential component $v_{1, d}^{*}, v_{2, d}^{*}, v_{3, d}^{*}$ will be imposed as a three-phase sinusoidal symmetrical system:

$$
\left\{\begin{array}{l}
v_{1, d}^{*}=V_{L} \sin (\omega t-\varphi) \\
v_{2, d}^{*}=V_{L} \sin (\omega t-\varphi-2 \pi / 3) \\
v_{3, d}^{*}=V_{L} \sin (\omega t-\varphi-4 \pi / 3)
\end{array},\right.
$$

where $V_{L}$ is the load voltage amplitude and $\omega$ is the angular frequency.

In the presence of a symmetrical load, given the high number of cells per arm, the three arm currents can be assumed to be sinusoidal and, in particular, since the circulating currents have been neglected, a three-phase sinusoidal symmetrical system can be considered:

$$
\left\{\begin{array}{l}
i_{1}=I_{L} \sin (\omega t) \\
i_{2}=I_{L} \sin (\omega t-2 \pi / 3), \\
i_{3}=I_{L} \sin (\omega t-4 \pi / 3)
\end{array}\right.
$$

where $I_{L}$ is the load current amplitude and $\varphi$ is the phase shift delay.

By defining $\xi=2 V_{L} / N V_{\text {cell }}$ as the arm modulation index, Equation (5) can be rewritten as

$$
v_{k, d}^{*}=N \xi V_{\text {cell }} / 2 \sin \left(\omega t-\alpha_{k}\right),
$$

where $\alpha_{k}=2 \pi(k-1) / 3$.

Equivalently, by introducing $\xi_{D C}=2 v_{0, D C}^{*} / N V_{\text {cell }}$, the DC component of $v_{0}^{*}$ can be written as

$$
v_{0, D C}^{*}=N \xi_{D C} V_{\text {cell }} / 2
$$

Based on Equations (7) and (8), Equation (3) can be written as

$$
v_{k}^{*}=\frac{N V_{\text {cell }}\left(\xi \sin \left(\omega t-\alpha_{k}\right)+\xi_{D C}\right)}{2}+v_{0, A C}^{*}
$$

From Equations (1) and (9), the number of modules $N_{o n}(t)$ switched ON at instant $t$ is

$$
N_{o n}(t)=\operatorname{round}\left(\frac{N\left(\xi \sin \left(\omega t-\alpha_{k}\right)+\xi_{D C}\right)}{2}+\frac{v_{0, A C}^{*}}{V_{\text {cell }}}\right) \text {. }
$$

If $N$ is large enough, $N_{o n}(t)$ can be reasonably approximated with its continuous equivalent:

$$
N_{c, o n}(t)=\frac{N\left(\xi \sin \left(\omega t-\alpha_{k}\right)+\xi_{D C}\right)}{2}+\frac{v_{0, A C}^{*}}{V_{c e l l}} .
$$

\section{DS-MMC}

With reference to Figure 1, while, for the SS-MMC, the arm currents are equal to the load currents, in the DS configuration, each $k$-th phase load current $i_{L k}$ is given by the difference of a TOP arm current $i_{k T}$ and a BOTTOM arm current $i_{k B}$. In fact, the DS- 
MMC can be seen as being composed of three star-connected TOP arms (with voltages $v_{1 T}, v_{2 T}, v_{3 T}$ ) and three star-connected BOTTOM arms (with voltages $v_{1 B}, v_{2 B}, v_{3 B}$ ):

$$
\text { TOP }:\left\{\begin{array}{l}
v_{0 T}^{*}=\left(v_{1 T}^{*}+v_{2 T}^{*}+v_{3 T}^{*}\right) / 3=v_{0 T, D C}^{*}+v_{0 T, A C}^{*} \\
v_{k T}^{*}=v_{k T, d}^{*}+v_{0 T}^{*} \\
v_{0 B}^{*}=\left(v_{1 B}^{*}+v_{2 B}^{*}+v_{3 B}^{*}\right) / 3=v_{0 B, D C}^{*}+v_{0 B, A C}^{*} \\
v_{k B}^{*}=v_{k B, d}^{*}+v_{0 B}^{*}
\end{array}\right.
$$

with symbols having similar meanings to those in the SS-MMC.

In a normal sinusoidal steady-state condition, and for each $k$-th phase, the differential component of the BOTTOM arm reference voltage lags the TOP one by an angle of $180^{\circ}$. Moreover, when the circulating currents are neglected, each BOTTOM arm current is opposed to the TOP one:

$$
\left\{\begin{array}{l}
v_{k B, d}^{*}=-v_{k T, d}^{*} \\
i_{k T}=-i_{k B}
\end{array}\right.
$$

Therefore, the DS-MMC is equivalent to two SS-MMCs and all of the previous considerations can be separately applied to both the three TOP arms and the three BOTTOM arms, with the only difference being that, in the presence of a symmetrical load, $i_{k T}=-i_{k B}=i_{L k} / 2$.

\section{Conventional Strategies and Cell Loss Calculation}

In conventional approaches $([3,4,10,11,24])$, the common mode voltage DC component $v_{0, D C}^{*}$ is equal to $N V_{\text {cell }} / 2$ (corresponding to $\xi_{D C}=1$ ), so that the arm reference voltages are centered in the range of the possible values $\left[0, N V_{\text {cell }}\right]$, while the AC component $v_{0, A C}^{*}$ is set to zero for $\xi \leq 1$. In order to achieve an overmodulation-free operation in the interval $\xi \in] 1,2 / \sqrt{3}], v_{0, A C}^{*}$ can be equal to either $v_{S V M}$ or $v_{T H I}$, with $v_{S V M}$ representing a traditional Space Vector Modulation (SVM) AC common mode component and $v_{T H I}$ representing a third harmonic of a proper amplitude:

$$
\begin{aligned}
& v_{0, D C}^{*}=N V_{\text {cell }} / 2 \\
& v_{0, A C}^{*}=\left\{\begin{array}{l}
0 \text { for } \xi \leq 1 \\
v_{S V M} \text { or } v_{T H I} \text { for } \xi>1
\end{array}\right.
\end{aligned}
$$

For the traditional SVM injection,

$$
v_{S V M}=\left\{\begin{array}{l}
\frac{N V_{\text {cell }} \xi \sin \left(\omega t-\frac{\pi}{3} h\right)}{4} \forall \omega t \in A_{p, h} \\
\frac{N V_{\text {cell }} \xi \sin \left(\omega t+\frac{2 \pi}{3}-\frac{\pi}{3} h\right)}{4} \forall \omega t \in A_{n, h}
\end{array},\right.
$$

where $\left\{\begin{array}{l}A_{p, h} \equiv(-\pi / 6+2 \pi / 3 h, \pi / 6+2 \pi / 3 h) \\ A_{h, h} \equiv(\pi / 6+2 \pi / 3 h, \pi / 2+2 \pi / 3 h)\end{array}\right.$ and $h$ is an integer number.

For the third harmonic injection,

$$
v_{T H I}=\frac{N V_{c e l l} \xi \sin 3 \omega t}{12} .
$$

Figure 2 shows the qualitative waveform of $v_{k, d}^{*}+v_{0, A C}^{*}$ (normalized with respect to $N V_{\text {cell }} / 2$ ) in the presence of the conventional AC common mode injection methods. In particular, starting from the differential component $v_{k, d}^{*}$ (Figure 2a), the $v_{T H I}$ or $v_{S V M}$ common mode AC component (Figure $2 b$ ) can be added, producing the waveform of Figure $2 \mathrm{c}$ or Figure $2 \mathrm{~d}$, respectively. 

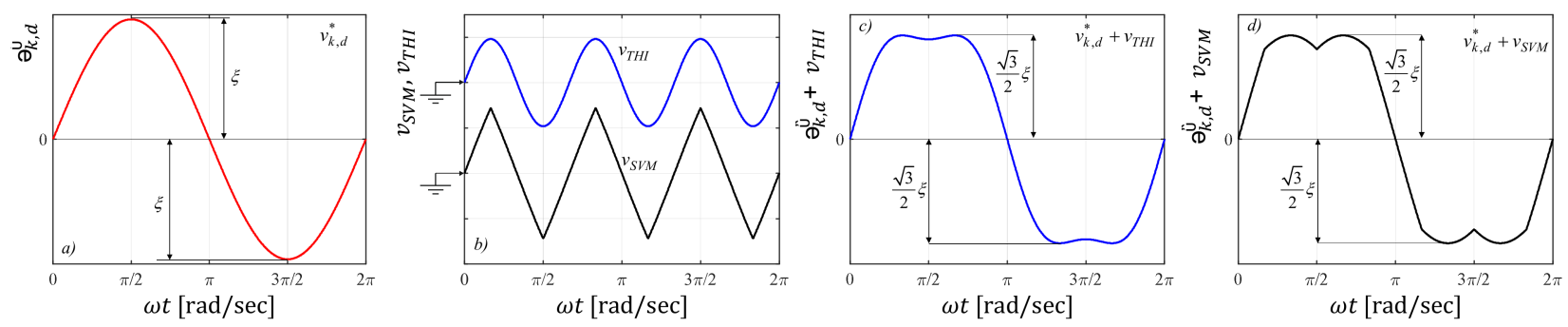

Figure 2. Qualitative waveform of the generic arm reference voltage in the presence of the conventional AC common mode injection: (a) Differential component; (b) AC conventional common mode components; and (c,d) total arm reference voltage AC component.

For the sake of clarity, Figure 2 can refer to either an SS-MMC or the three TOP arms of a DS-MMC, while for the BOTTOM arms, the corresponding waveforms are shifted by $180^{\circ}$.

Thanks to the symmetry of the MMC arms (for both SS and DS configurations), the cell power loss calculation can be performed with reference to a single arm. In particular, if a cell is modeled as a DC voltage source with a series resistance $R_{\text {cell }}$, the instantaneous power dissipated into the arm cells $p_{J}(t)$ can be expressed as a function of $N_{c, \text { on }}$ :

$$
p_{J}(t)=N_{c, o n}(t) R_{\text {cell }} i_{a}^{2}(t),
$$

where $i_{a}$ is the instantaneous arm current. By substituting Equation (11) into Equation (17), the average power losses are given by

$$
P_{J}=\frac{1}{T} \int_{0}^{T} N_{c, \text { on }} R_{\text {cell }} i_{a}^{2} \mathrm{~d} t=R_{\text {cell }}\left(\frac{N \xi_{D C} I_{a}^{2}}{4}+\frac{1}{T} \int_{0}^{T} \frac{v_{0, A C}^{*}}{V_{\text {cell }}} i_{a}^{2} \mathrm{~d} t\right) .
$$

By replacing $v_{0, A C}^{*}$ in Equation (18) with its Fourier-series $\sum_{n=1}^{n=+\infty} V_{a c, h} \sin \left(n \omega t-\varphi_{a c, n}\right)$, $P_{J}$ is derived:

$$
P_{J}=R_{\text {cell }}\left(\frac{N \xi_{D C}}{4}-\frac{V_{a c, 2}}{V_{\text {cell }}} \sin \left(2 \varphi-\varphi_{a c, 2}\right)\right) I_{a}^{2} .
$$

According to conventional strategies, considering that $\xi_{D C}=1$ and that $v_{S V M}$ and $v_{T H I}$ do not contain the second harmonic, $P_{J}$ becomes

$$
P_{J}=N R_{c e l l} I_{a}^{2} / 4
$$

where $I_{a}$ is the arm current amplitude: $I_{a}=I_{L}$ for the SS-MMC and $I_{a}=I_{L} / 2$ for the DS-MMC.

\section{Cell Loss Comparison of MMC and VSI}

From Equation (19), it is straightforward to compute the total cell power loss for either a three-phase SS-MMC or DS-MMC characterized by the same number $N$ of cells per arm:

$$
\left\{\begin{array}{l}
P_{J, S S-M M C}=\frac{3}{4} N R_{c e l l, S S} I_{L}^{2} \\
P_{J, D S-M M C}=\frac{3}{8} N R_{c e l l, D S} I_{L}^{2}
\end{array} .\right.
$$

In order to produce the same AC output voltage, the SS-MMC converter requires half as many modules compared to the DS-MMC, where, for each phase, two arms are parallel-connected with respect to the AC side. As a result, for the same total system storage capacity, an SS-MMC cell can be regarded as equivalent to two parallel-connected DS-MMC cells, i.e., $R_{\text {cell }, D S} \cong 2 R_{\text {cell,SS}}$. Therefore, $P_{J, S S-M M C} \cong P_{J, D S-M M C}$. 
The mean value of the load active power $P_{L}$ is naturally independent of the converter configuration:

$$
P_{L}=\frac{3}{2} V_{L} I_{L} \cos \varphi=\frac{3}{4} \xi N V_{c e l l} I_{L} \cos \varphi .
$$

The cell power losses in the MMC (henceforth indicated as $P_{J, M M C}$ for both the SSMMC and DS-MMC) can be compared to the cell losses $P_{J, V S I}$ occurring in a traditional two-level Voltage Source Inverter (VSI). An equivalent VSI battery pack may be built using three parallel-connected stacks of $N$ cells, as shown in Figure 3. A DC-side $L C$ filter ensures that a smooth DC current $i_{d c}$ is drawn from the pack.

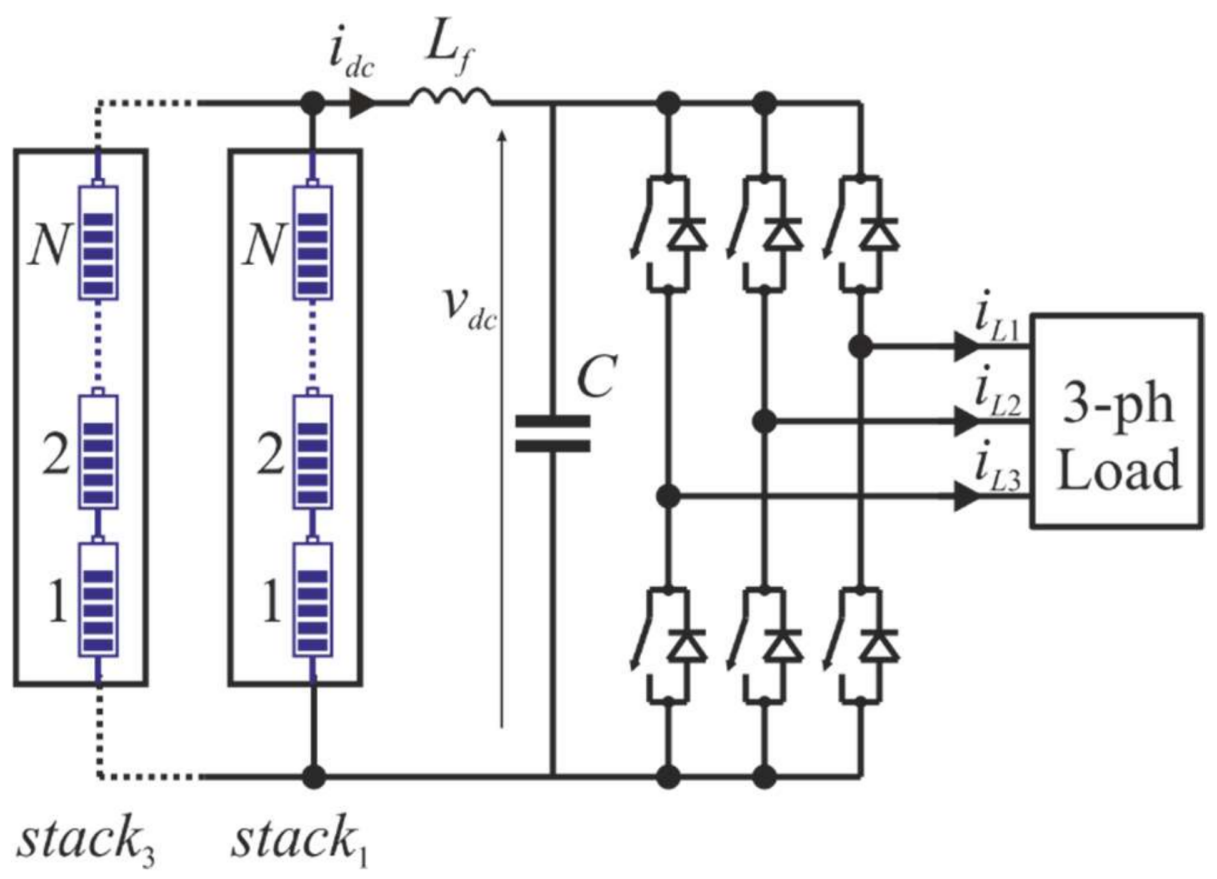

Figure 3. Voltage Source Inverter (VSI).

In this configuration, each stack effectively corresponds to the cells contained in the modules of one SS-MMC arm. If the VSI switching frequency $f_{s}$ is much greater than the fundamental output frequency $f$, the current $i_{d c}$ flowing in the battery pack can be assumed to be constant once the DC filter components have been properly chosen. If the converter losses are neglected, $i_{d c}$ only depends on $P_{L}$ :

$$
i_{d c}=\frac{P_{L}}{N V_{\text {cell }}}=\frac{3}{4} \xi I_{L} \cos \varphi .
$$

From Equation (23), the cell losses are

$$
P_{J, V S I}=\frac{1}{3} N R_{\text {cell }} i_{d c}^{2}=\frac{3}{16} N R_{\text {cell }}\left(\xi I_{L} \cos \varphi\right)^{2} .
$$

This may be directly compared with the first of Equation (21) with $R_{\text {cell,SS }}=R_{\text {cell }}$ (or with the second of Equation (21) with $R_{\text {cell,DS }}=2 R_{\text {cell }}$ ).

As it can be noted, the VSI cell losses depend on both the modulation index and the load power factor (in fact, $P_{J, V S I} \propto P_{L}^{2}$ ). On the contrary, $P_{J, M M C}$ does not depend on $\xi$ or $\cos \varphi$, i.e., at constant $I_{L}$, the cell losses do not depend on the output power. Moreover, it is evident that $P_{I, M M C}$ is considerably higher than $P_{I, V S I}$; in the case of the unitary power factor and full modulation index, the cell losses in the MMC are four times those of the VSI (i.e., Equation (21) divided by Equation (24)). 


\section{Proposed Optimum Injection Strategy}

With reference to a three-phase system, $v_{0, A C}^{*}$ is built on multiples of the third harmonic in order to keep the arm reference voltages symmetrical across the converter phases. In this context, as per Equation (19), $P_{J}$ does not directly depend on $v_{0, A C}^{*}$. Nevertheless, a proper $v_{0, A C}^{*}$ injection law can be formulated in order to decrease the minimum settable value of $\tilde{\xi}_{D C}$, to which, as stated by Equation (19), the arm cell losses are proportional. $\xi_{D C}$ can be regarded as the shift to be applied to the AC component of the arm reference voltage $\left(v_{k, d}^{*}+v_{0, A C}^{*}\right)$ in order to guarantee that $v_{k}^{*} \in\left[0, N V_{\text {cell }}\right]$. Therefore, the range of possible values for $\tilde{\xi}_{D C} \in\left[\xi_{D C, \min }, \xi_{D C, \max }\right]$ depends on both the modulation index $\xi$ and on $v_{0, A C}^{*}$. The cell loss minimization problem can thus be reduced to the formulation of an optimal injection law able to minimize $\xi_{D C \text {, min }}$ for each $\xi \in[0,2 / \sqrt{3}]$. The proposed common mode voltage injection law is based on the following AC component:

$$
v_{0, A C, O P T}=-\frac{N V_{\text {cell }} \xi\left(\sin \left(\omega t-\frac{2 \pi}{3} h\right)+\frac{3 \sqrt{3}}{2 \pi}\right)}{2} \forall \omega t \in A_{h}
$$

where $A_{h} \equiv(7 \pi / 6+2 \pi / 3 h, 7 \pi / 6+2 \pi / 3(h+1))$ and $h$ is an integer number.

Figure 4 a shows the qualitative waveform of $v_{0, A C, O P T}$, while the total $\mathrm{AC}$ arm reference voltage $v_{k, d}^{*}+v_{0, A C, O P T}$ (normalized with respect to $N V_{\text {cell }} / 2$ ) is shown in Figure $4 \mathrm{~b}$; as previously mentioned, for the BOTTOM arms of the DS-MMC, a $180^{\circ}$ shift must be considered.
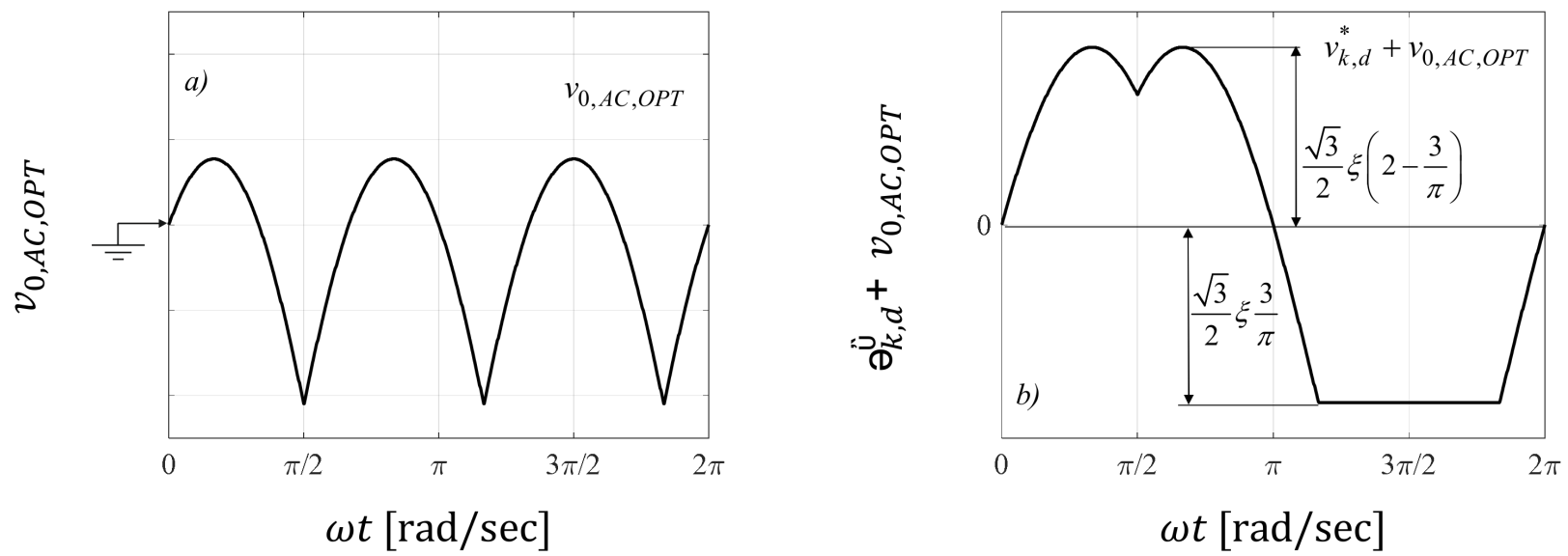

Figure 4. Qualitative waveform of the generic arm reference voltage in the presence of the proposed AC common mode injection: (a) AC proposed common mode components, and (b) total AC arm reference voltage.

As can be noted from Figure $2 \mathrm{a}$, when $v_{0, A C}^{*}=0$, i.e., no injection is used, the minimum $\xi_{D C}$ value, necessary to shift the resultant arm reference voltage such that $v_{k}^{*} \geq 0$, is equal to the modulation index $\xi$ (i.e., $\xi_{D C \text {, min }}=\xi$ ). Instead, in both cases, when $v_{0, A C}^{*}=v_{S V M}$ or $v_{0, A C}^{*}=v_{T H I}$, it is $\xi_{D C, \min }=\sqrt{3} \xi / 2$ (Figure 2c,d). On the other hand, the proposed optimum law gives $\xi_{D C \text {, min }}=3 \sqrt{3} \xi / 2 \pi$ (Figure $4 b$ ), which is the lowest of the three values.

The proposed strategy can be summarized by

$$
\left\{\begin{array}{l}
v_{0, A C}^{*}=v_{0, A C, O P T} \\
\xi_{D C}=3 \sqrt{3} \xi / 2 \pi
\end{array} \Rightarrow P_{J, o p t}=\frac{3 \sqrt{3}}{8 \pi} \xi R_{\text {cell }} I_{a}^{2} .\right.
$$

In order to verify that this is actually the optimum voltage injection law, which guarantees the lowest $\xi_{D C \text {, min }}$, leading to the lowest cell losses of a three-phase MMC, it is convenient to consider the constrains Equation (4). In the possible range $v_{0, \text { min }}^{*} \leq$ $v_{0}^{*} \leq v_{0, \text { max }}^{*}$, it is evident that the choice $v_{0}^{*}=v_{0, \min }^{*}$ minimizes the quantity $\xi_{D C}$, thus guaranteeing the lowest cell losses. On the other hand, it is easy to verify that the DC 
component of $v_{0, \min }^{*}$ can be obtained by Equation (8), with $\xi_{D C}=3 \sqrt{3} \xi / 2 \pi$, while its AC component corresponds to the $v_{0, A C, O P T}$ of Equation (15). It can be pointed out that the lower achievable $\xi_{D C \text {, min }}$ is linked to the asymmetrical waveform of $v_{0, A C, O P T}$, which leads to a lower injected absolute minimum value (Figure $4 \mathrm{~b}$ ) with respect to the other methods.

Applying the proposed method, the total cell power losses for an SS-MMC and a DS-MMC characterized by the same number of cells per arm $(N)$ are

$$
\left\{\begin{array}{l}
P_{J, o p t, S S-M M C}=\frac{9 \sqrt{3}}{8 \pi} \xi N R_{c e l l, S S} I_{L}^{2} \\
P_{J, o p t, D S-M M C}=\frac{9 \sqrt{3}}{16 \pi} \xi N R_{c e l l, D S} I_{L}^{2}
\end{array} .\right.
$$

It should be noted that in the case of a DS-MMC whose DC side is not isolated (see Figure 1), the power loss minimization techniques cannot be employed since $\xi_{D C}$ is constrained to the total DC-link voltage value.

By comparing Equation (27) with Equation (21), the cell energy saving $\left(P_{J}-P_{J, o p t}\right) / P_{J}$ guaranteed by the proposed method is linear with $\xi$, and in particular, it is equal to $100 \%$ for $\xi=0$ and around $5 \%$ for $\xi=2 / \sqrt{3}$.

As an example, if a grid connected MMC is sized such that $\mathrm{SoC}=0$ corresponds to the maximum modulation index $\xi=2 / \sqrt{3}$ (worst case for evaluating the benefit of the proposed technique), during a complete charge (or discharge) cycle, and considering the typical lithium cell voltage variation, the modulation index will vary from $2 / \sqrt{3}$ to about 0.9 , with an average $\xi$ value equal to about 1 . The corresponding average energy saving is equal to about $17.5 \%$. Naturally, in an application characterized by a lower value of $\xi$, the improvement is even more significant. It is important to note, however, that, even with a unitary power factor and full modulation index, an MMC operated with the optimal injection law will still cause approximately 3.3 times the cell loss of an equivalent VSI (i.e., Equation (26) divided by Equation (24)). In practice, the choice between an MMC and VSI design must involve a careful trade-off between the significantly higher cell loss incurred by the MMC and the inherent modularity, BMS flexibility, low EMI, and high-voltage advantages that an MMC has over a VSI.

\section{Experimental Validation}

To validate the power loss minimization method presented in section $V$, the experimental setup of Figure 5 was used.
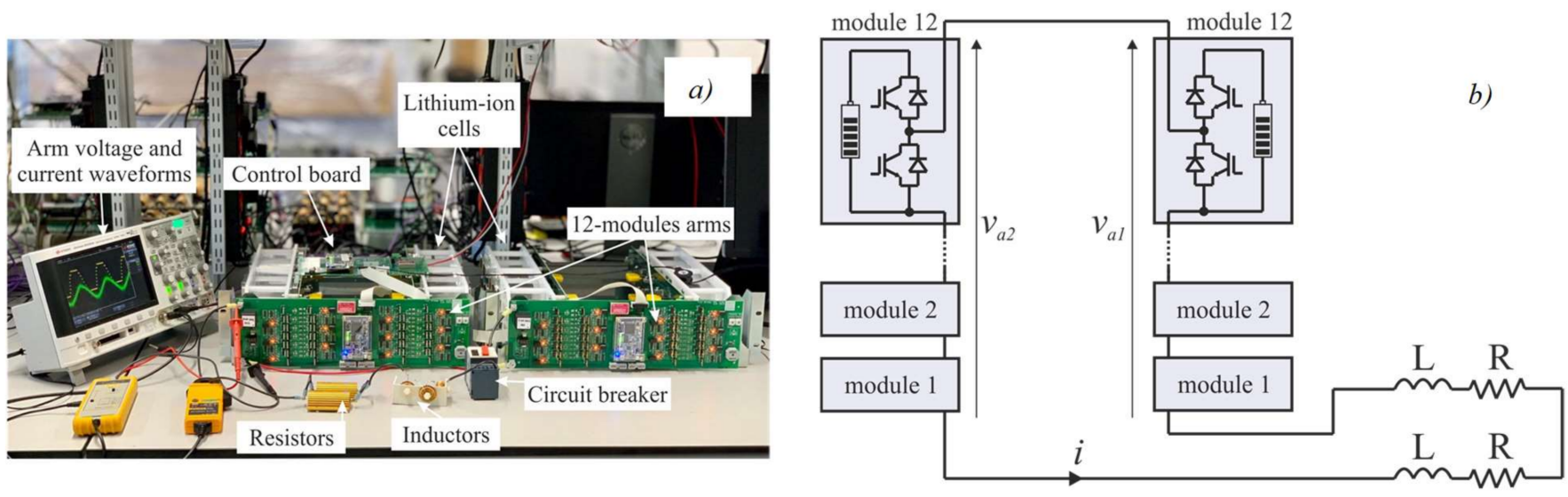

Figure 5. Experimental setup: (a) Photograph and (b) schematic.

Each arm in Figure 5 comprises twelve modules connected in series. Each module includes a $20 \mathrm{Ah}$ lithium titanate cell that is individually controlled by an H-bridge converter (a detailed description of the control architecture of the experimental hardware is 
presented in [16]). In these experiments, each H-bridge is operated as a half-bridge, only allowing for a positive or zero voltage output.

Detailed characteristics of the setup and experiments are presented in Table 1. According to the cell loss minimization techniques explained in the previous section and, in particular, by changing the settings of the variables $\xi_{D C}$ and $v_{a, 0, A C}^{*}$, four different tests were performed.

Table 1. Details of the performed tests and results.

\begin{tabular}{|c|c|c|c|c|}
\hline$N$ & \multicolumn{4}{|c|}{12} \\
\hline$V_{\text {cell }}(\mathrm{V})$ & \multicolumn{4}{|c|}{2.5} \\
\hline$R_{\text {cell }}(\mathrm{m} \Omega)$ & \multicolumn{4}{|c|}{5} \\
\hline$\xi$ & \multicolumn{4}{|c|}{$2 / 3$} \\
\hline$v_{a 1, d}^{*}$ & \multicolumn{4}{|c|}{$10 \cos (2 \pi 50 t)$} \\
\hline$v_{a 2, d}^{*}$ & \multicolumn{4}{|c|}{$10 \cos (2 \pi 50 t+2 \pi / 3)$} \\
\hline$R(\Omega)$ & \multicolumn{4}{|c|}{7.5} \\
\hline$L(\mathrm{mH})$ & \multicolumn{4}{|c|}{3.125} \\
\hline$P_{\operatorname{arm}}(\mathrm{W})$ & \multicolumn{4}{|c|}{3.88} \\
\hline Test $n^{\circ}$ & $\begin{array}{c}1 \\
\text { Conventional } \\
\text { method }\end{array}$ & 2 & 3 & $\begin{array}{c}4 \\
\begin{array}{c}\text { Proposed } \\
\text { method }\end{array}\end{array}$ \\
\hline$\xi_{d c}$ & 1 & $2 / 3$ & $1 / \sqrt{3}$ & $3 \sqrt{3} \xi / 2 \pi$ \\
\hline$v_{a, 0, A C}^{*}$ & 0 & 0 & $v_{T H I}$ & $v_{0, A C, O P T}$ \\
\hline$P_{J}(\mathrm{~mW})$ & 14.56 & 9.75 & 8.47 & 7.95 \\
\hline$P_{J}^{\prime}(\mathrm{mW})$ & 14.67 & 9.83 & 8.43 & 8.12 \\
\hline $\begin{array}{l}\text { Error }(\%) \\
100 \frac{P_{J}-P_{I}^{\prime}}{P_{I}^{\prime}}\end{array}$ & -0.76 & -0.84 & 0.48 & -2.13 \\
\hline
\end{tabular}

Test 1 refers to the conventional method: $v_{0, A C}^{*}=0$ and $\xi_{D C}=1$.

In Test 2, no AC voltage injection was used, but $\xi_{D C}$ was set to a lower value $\left(\xi_{D C}=2 / 3\right.$ instead of $\left.\xi_{D C}=1\right)$.

In Test 3 , a third harmonic AC voltage injection was added and $\xi_{D C}$ was further decreased to $1 / \sqrt{3}$.

Test 4 refers to the optimum proposed method with $v_{0, A C}^{*}=v_{0, A C, O P T}$ and $\xi_{D C}=3 \sqrt{3} \xi / 2 \pi$.

For each test, the current and voltage of one arm were sampled through the oscilloscope at a frequency of $25 \mathrm{MHz}$ (500 k samples per $50 \mathrm{~Hz}$ period). Each cell current was calculated as follows:

$$
i_{c e l l, n}(k)=g_{n}(k) i_{a}(k),
$$

where $i_{\text {cell, } n}(k)$ is the current of the $n$-th cell at the sampling time $k, i_{a}(k)$ is the arm current measured at the sample point $k$, and $g_{n}(k)$ is the switching signal:

$$
g_{n}(k)=\left\{\begin{array}{l}
0, \text { if } v_{a 1}(k)<n V_{\text {cell }}(n-\text { cell bypassed }) \\
1, \text { if } v_{a 1}(k) \geq n V_{\text {cell }}(n-\text { cell online })
\end{array} .\right.
$$

For each test, the total cell loss of the considered arm is calculated by

$$
P_{J}^{\prime}=\frac{R_{\text {cell }}}{N_{s}} \sum_{k=1}^{N_{s}} \sum_{n=1}^{12} g_{n}(k) i_{a}^{2}(k)
$$

where $N_{S}$ is the total number of samples per cycle. 
Table 1 reports these results, together with the theoretical calculation of $P_{J}$. All the tests were carried out in correspondence with the same modulation index value, such that the arm output power $P_{\text {arm }}$ was fixed. The error between the experimental and theoretical results, which is also shown, is less than $2.5 \%$ for all cases (within the experimental error, e.g., due to arm current measurements).

As can be noted from the Test 1 results (Figure 6a,e), the arm voltage is centered around $15 \mathrm{~V}\left(N V_{\text {cell }} / 2\right)$ and its waveform corresponds to a quantized sine wave. The theoretical calculated cell losses (see Table 1) are substantially equal to the experimental ones.

Test 1 (Conventional method)
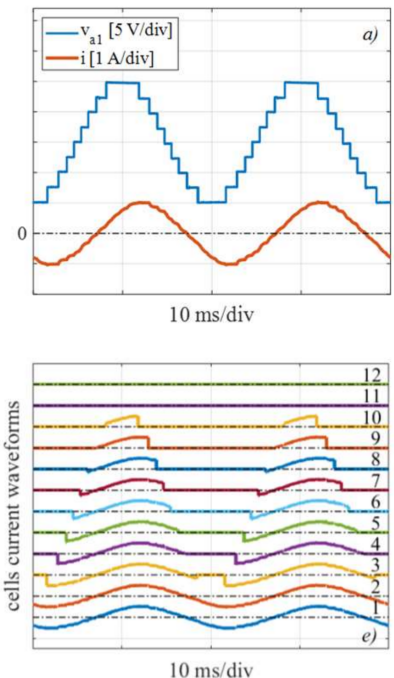

Test 2

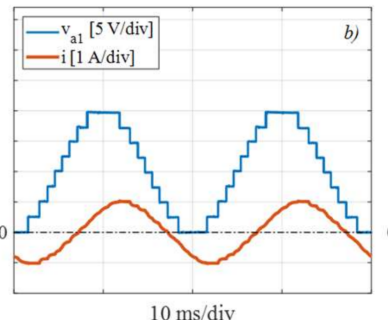

$10 \mathrm{~ms} / \mathrm{div}$

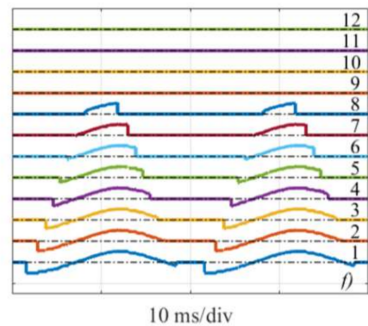

Test 3

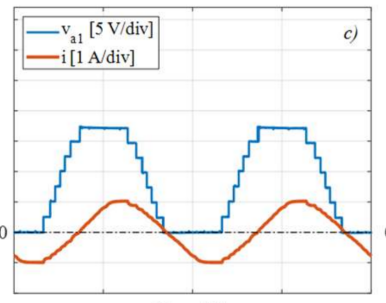

$10 \mathrm{~ms} / \mathrm{div}$

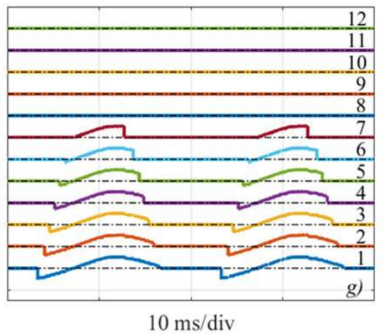

Test 4

(Proposed method)
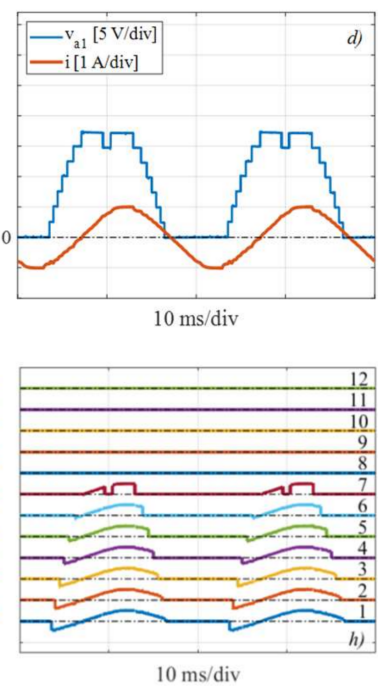

Figure 6. Experimental results: total voltage and current during: (a) Test 1, (b) Test 2, (c) Test 3, (d) Test 4; cells currents waveform during: (e) Test 1, (f) Test 2, (g) Test 3, (h) Test 4.

As per the theoretical considerations, the Test 2 results testify that the cell losses are dependent on $v_{0, D C}^{*}$. Indeed, in comparison with Test 1 , the losses are lower, proportional to the decrease of $\xi_{D C}$. From Figure $6 \mathrm{~b}$, it can be noted that the arm voltage reaches the zero value. In fact, the $\xi_{D C}$ setting of Test 2 corresponds to the minimum $\xi_{D C}$ value, considering that no AC common mode voltage has been injected.

Test 3 clarifies that even if $P_{J}$ does not directly depend on $v_{0, A C}^{*}$, an AC injection can affect the minimum settable value of $\xi_{D C}$. In this case, indeed, it was possible to set $\xi_{D C}=1 / \sqrt{3}$, without violating $0 \leq v_{k}^{*} \leq N V_{\text {cell }}$. The third injected harmonic can be recognized from the altered waveform of the arm voltage (Figure $6 \mathrm{c}$ ), which shows a wider constant value in correspondence with the maximum and minimum point.

Finally, the optimum AC common mode voltage injection of Test 4, which displays visible notches in the arm voltage (Figure 6d), guarantees the minimum settable value of $\xi_{D C}$, leading to the minimization of cell losses. The decrease of the cell losses is associated with a decrease of the total rms current value in the 12 cells, which can be easily noted when compared to Figure $6 \mathrm{e}, \mathrm{h}$. In comparison with the conventional method of Test 1 , the proposed method assures a cell energy saving of about $45 \%$, which is consistent with the fact that the experimental converter is operating with a mid-range $\xi$ value.

\section{Additional Losses Numerical Example}

In order to better evaluate the relative impact of the cell loss reduction introduced by the proposed method, other losses occurring in the system should be considered. These are principally switching and conduction losses occurring in the power electronic devices. For an MMC with a large number of modules driven by NLM, the switching losses are negligible, since the power devices switch at the fundamental output frequency. The VSI is 
instead characterized by both conduction and switching losses. A rapid example can be developed by completing the analysis of [11] (which compares the power electronics losses of a traditional VSI to those of a DS-MMC) with the electrochemical cell losses evaluation of the present work. While the VSI is equipped with FZ300R12KE3G IGBT, the MMC is built upon AUIRFS8409-7P power MOSFET. Both solutions constitute a $80 \mathrm{~kW}-220 \mathrm{~V}-250 \mathrm{~A}$ converter, fed by a $24 \mathrm{kWh}$ battery system based on 11 Ah Kokam SLPB55205130H cells with an internal resistance of approximately $1.6 \mathrm{~m} \Omega$ each.

The procedure given in [11] only considers the losses occurring in the power electronic devices; at half full-load, with $\xi=0.7$ and $\cos \varphi=1$, the power electronics losses are as shown in Figure 7a.

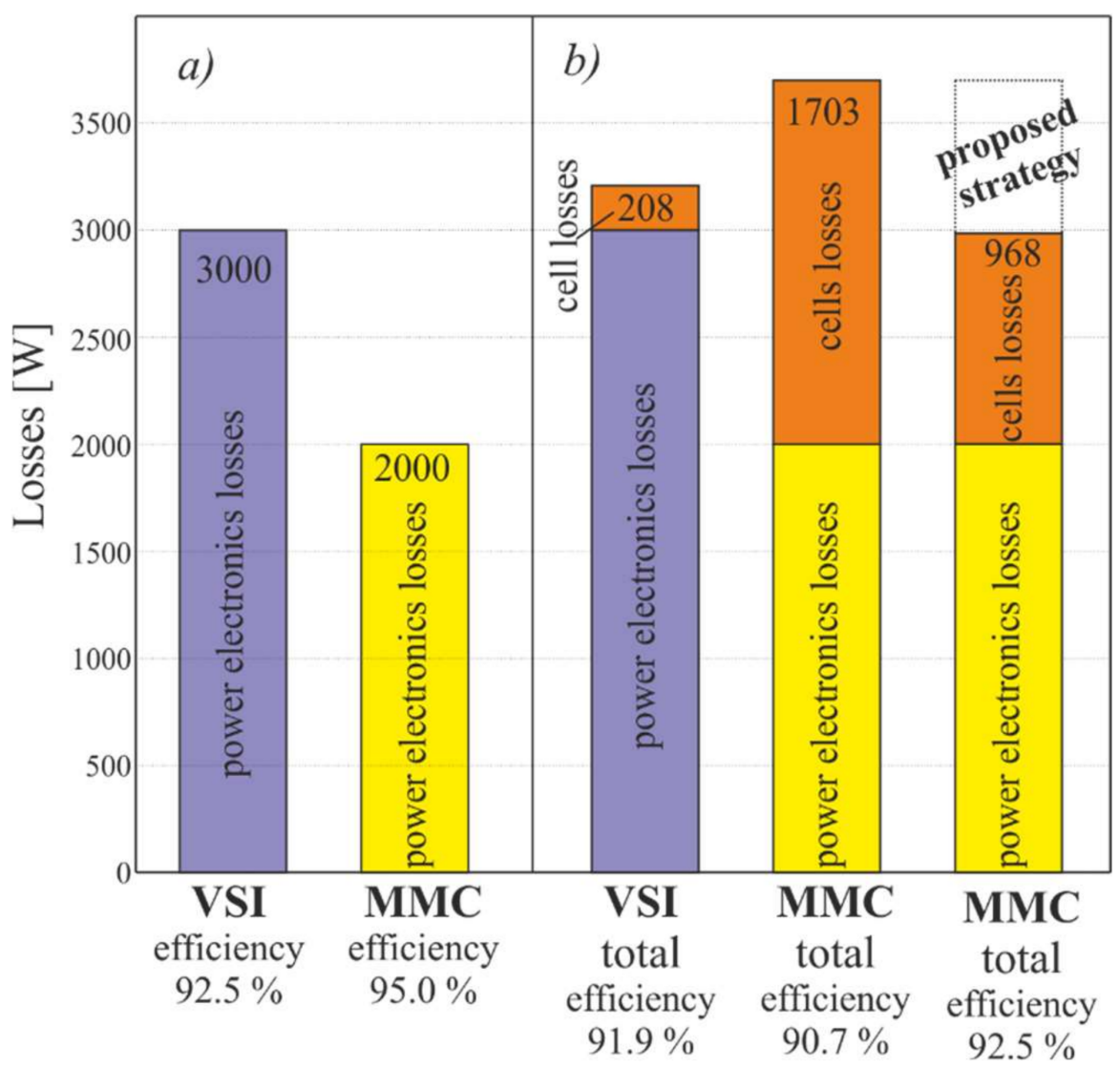

Figure 7. (a) Power losses of an $80 \mathrm{~kW}-24 \mathrm{kWh}$ converter realized by the MMC and VSI solution: (a) Power electronics losses and (b) all losses.

Cell losses may be added to the analysis of [11], by applying Equations (21), (24) and (27), resulting in the loss breakdown given in Figure $7 \mathrm{~b}$. As expected, the MMC cell losses are higher than those of VSI and represent an important fraction of the total losses. In this example, the proposed technique produces a $42 \%$ reduction in cell losses, which equates to an overall $19 \%$ loss reduction. As a consequence of applying the proposed technique, the total efficiency is increased by $1.8 \%$.

Naturally, the actual increase of the MMC overall efficiency achieved through the proposed technique depends on the particular operating condition. It is important to highlight that loss reduction in electrochemical cells is doubly beneficial as it leads to a direct reduction in detrimental cell heating and increase in the service life.

\section{Conclusions}

In the present work, the calculation of the cell losses for Modular Multilevel Converters (MMCs) equipped with half-bridge modules, each directly connected to an elementary 
electrochemical cell and driven by Nearest Level Control (NLC), has been generalized for any common mode voltage value. It was observed that the total cell losses of both a Single Star MMC and a Double Star MMC are significantly higher than those occurring in an equivalent VSI.

The novel analytical investigation allowed the development of an optimal common mode voltage injection law that minimizes the cell power losses under all balanced operating conditions. The proposed method delivers a significant reduction in cell losses, which is dependent on the converter working condition and, in particular, is about $17.5 \%$ in the worst case.

All of the analytical derivations have been validated by means of an experimental set-up based on a two-arm SS-MMC with 12 modules per arm, showing an error within $2.5 \%$ in all the considered cases and confirming the effectiveness of the proposed technique, with a cell loss reduction of about $45 \%$ in the performed tests.

In conclusion, in comparison with conventional VSI solutions, MMC solutions show intrinsic advantages (modularity, BMS functionality, fault tolerance, reduced EMI issue, etc.), but are characterized by higher cell losses, which represent an important fraction of the total losses. The proposed optimum common mode voltage injection law introduces a significant reduction of the converter losses, making MMCs more attractive with respect to conventional power converters.

Author Contributions: Conceptualization, G.B. and I.S.; methodology, D.R. and I.S.; software, E.C.; validation, D.R. and G.B.; formal analysis, D.R.; investigation, E.C. and I.S.; data curation, G.B. and E.C.; writing—original draft preparation, G.B., E.C. and I.S.; writing-review and editing, D.R.; supervision, I.S. All authors have read and agreed to the published version of the manuscript.

Funding: This research received no external funding.

Institutional Review Board Statement: Not applicable.

Informed Consent Statement: Not applicable.

Conflicts of Interest: The authors declare no conflict of interest.

\section{References}

1. Jafari, M.; Malekjamshidi, Z.; Li, L.; Zhu, J.G. Performance analysis of full bridge, boost half bridge and half bridge topologies for application in phase shift converters. In Proceedings of the 2013 International Conference on Electrical Machines and Systems (ICEMS), Busan, Korea, 26-29 October 2013; pp. 1589-1595.

2. Coppola, M.; Del Pizzo, A.; Iannuzzi, D. A power traction converter based on Modular Multilevel architecture integrated with energy storage devices. In Proceedings of the 2012 Electrical Systems for Aircraft, Railway and Ship Propulsion, Bologna, Italy, 16-18 October 2012; pp. 1-7.

3. Diab, M.S.; Elserougi, A.A.; Massoud, A.M.; Ahmed, S.; Williams, B.W. A Hybrid Nine-Arm Modular Multilevel Converter for Medium-Voltage Six-Phase Machine Drives. IEEE Trans. Ind. Electron. 2019, 66, 6681-6691. [CrossRef]

4. Akagi, H. Classification, terminology, and application of the modular multilevel cascade converter (MMC). IEEE Trans. Ind. Electron. 2011, 26, 3119-3130.

5. Camargo, R.S.; Mayor, D.S.; Miguel, A.M.; Bueno, E.J.; Encarnação, L.F. A Novel Cascaded Multilevel Converter Topology Based on Three-Phase Cells-CHB-SDC. Energies 2020, 13, 4789. [CrossRef]

6. Lamb, J.; Mirafzal, B.; Blaabjerg, F. PWM Common Mode Reference Generation for Maximizing the Linear Modulation Region of CHB Converters in Islanded Microgrids. IEEE Trans. Ind. Electron. 2018, 65, 5250-5259. [CrossRef]

7. Cheng, Q.; Wang, C.; Wang, J. Analysis on Displacement Angle of Phase-Shifted Carrier PWM for Modular Multilevel Converter. Energies 2020, 13, 6743. [CrossRef]

8. Tolbert, L.M.; Peng, F.Z. Multilevel converters for large electric drives. In Proceedings of the Applied Power Electronics Conference and Exposition, Thirteenth Annual, Anaheim, CA, USA, 15-19 February 1998; Volume 2, pp. 530-536.

9. Tolbert, L.M.; Chiasson, J.N.; McKenzie, K.J.; Du, Z. Control of cascaded multilevel converters with unequal voltage sources for HEVs. In Proceedings of the IEEE International Electric Machines and Drives Conference, 2003. IEMDC'03, Madison, WI, USA, 1 June 2003; Volume 2, pp. 663-669.

10. Quraan, M.; Yeo, T.; Tricoli, P. Design and Control of Modular Multilevel Converters for Battery Electric Vehicles. IEEE Trans. Power Electron. 2016, 31, 507-517. [CrossRef]

11. Quraan, M.; Tricoli, P.; D'Arco, S.; Piegari, L. Efficiency Assessment of Modular Multilevel Converters for Battery Electric Vehicles. IEEE Trans. Power Electron. 2017, 32, 2041-2051. [CrossRef] 
12. Brando, G.; Dannier, A.; Spina, I.; Tricoli, P. Integrated BMS-MMC Balancing Technique Highlighted by a Novel Space-Vector Based Approach for BEVs Application. Energies 2017, 10, 1628. [CrossRef]

13. Maharjan, L.; Inoue, S.; Akagi, H. A Transformerless Energy Storage System Based on a Cascade Multilevel PWM Converter with Star Configuration. IEEE Trans. Ind. Appl. 2008, 44, 1621-1630. [CrossRef]

14. Hillers, A.; Biela, J. Fault-tolerant operation of the modular multilevel converter in an energy storage system based on split batteries. In Proceedings of the 2014 16th European Conference on Power Electronics and Applications, Lappeenranta, Finland, 26-28 August 2014; pp. 1-8.

15. Chatzinikolaou, E.; Rogers, D.J. A Comparison of Grid-Connected Battery Energy Storage System Designs. IEEE Trans. Power Electron. 2017, 32, 6913-6923. [CrossRef]

16. Chatzinikolaou, E.; Rogers, D.J. Cell SoC Balancing Using a Cascaded Full-Bridge Multilevel Converter in Battery Energy Storage Systems. IEEE Trans. Ind. Electron. 2016, 63, 5394-5402. [CrossRef]

17. Wang, S.; Alsokhiry, F.S.; Adam, G.P. Impact of Submodule Faults on the Performance of Modular Multilevel Converters. Energies 2020, 13, 4089. [CrossRef]

18. Li, J.; Yin, J. Fault-Tolerant Control Strategies and Capability without Redundant Sub-Modules in Modular Multilevel Converters. Energies 2019, 12, 1726. [CrossRef]

19. Wang, Z.; Lin, H.; Ma, Y. A Control Strategy of Modular Multilevel Converter with Integrated Battery Energy Storage System Based on Battery Side Capacitor Voltage Control. Energies 2019, 12, 2151. [CrossRef]

20. Lawder, M.T.; Suthar, B.; Northrop, P.W.; De, S.; Hoff, C.M.; Leitermann, O.; Crow, M.L.; Santhanagopalan, S.; Subramanian, V.R. Battery Energy Storage System (BESS) and Battery Management System (BMS) for Grid-Scale Applications. Proc. IEEE 2014, 102, 1014-1030. [CrossRef]

21. Chatzinikolaou, E.; Rogers, D.J. Performance Evaluation of Duty Cycle Balancing in Power Electronics Enhanced Battery Packs Compared to Conventional Energy Redistribution Balancing. IEEE Trans. Power Electron. 2018, 33, 9142-9153. [CrossRef]

22. Uddin, W.; Zeb, K.; Adil Khan, M.; Ishfaq, M.; Khan, I.; Islam, S.u.; Kim, H.-J.; Park, G.S.; Lee, C. Control of Output and Circulating Current of Modular Multilevel Converter Using a Sliding Mode Approach. Energies 2019, 12, 4084. [CrossRef]

23. Moranchel, M.; Bueno, E.J.; Rodriguez, F.J.; Sanz, I. Implementation of nearest level modulation for Modular Multilevel Converter. In Proceedings of the 2015 IEEE 6th International Symposium on Power Electronics for Distributed Generation Systems (PEDG), Aachen, Germany, 22-25 June 2015; pp. 1-5.

24. Gonçalves, J.; Rogers, D.J.; Liang, J. Submodule Temperature Regulation and Balancing in Modular Multilevel Converters. IEEE Trans. Ind. Electron. 2018, 65, 7085-7094. [CrossRef] 